Project Report

\title{
Changing Attitudes toward the COVID-19 Vaccine among North Carolina Participants in the COVID-19 Community Research Partnership
}

Chukwunyelu H. Enwezor ${ }^{1, *} \mathbb{0}$, James E. Peacock, Jr. ${ }^{1}$, Austin L. Seals ${ }^{2}$, Sharon L. Edelstein ${ }^{3}$, Amy N. Hinkelman ${ }^{4}{ }^{(}$, Thomas F. Wierzba ${ }^{1}$, Iqra Munawar ${ }^{1}$, Patrick D. Maguire ${ }^{5}$, William H. Lagarde ${ }^{6}$, Michael S. Runyon ${ }^{7}$, Michael A. Gibbs ${ }^{7}$, Thomas R. Gallaher ${ }^{8}$, John W. Sanders III ${ }^{1,+}$ and David M. Herrington ${ }^{2,+}+$ (i)

check for updates

Citation: Enwezor, C.H.; Peacock, J.E., Jr.; Seals, A.L.; Edelstein, S.L.; Hinkelman, A.N.; Wierzba, T.F.; Munawar, I.; Maguire, P.D.; Lagarde, W.H.; Runyon, M.S.; et al. Changing Attitudes toward the COVID-19 Vaccine among North Carolina Participants in the COVID-19 Community Research Partnership. Vaccines 2021, 9, 916. https:/ / doi.org/10.3390/vaccines 9080916

Academic Editors: Barbara Rath and Anthony R. Mawson

Received: 14 May 2021

Accepted: 8 August 2021

Published: 17 August 2021

Publisher's Note: MDPI stays neutral with regard to jurisdictional claims in published maps and institutional affiliations.

Copyright: (C) 2021 by the authors Licensee MDPI, Basel, Switzerland. This article is an open access article distributed under the terms and conditions of the Creative Commons Attribution (CC BY) license (https:// creativecommons.org/licenses/by/ $4.0 /)$.
1 Department of Internal Medicine, Section on Infectious Diseases, Wake Forest School of Medicine, Winston-Salem, NC 27517, USA; jpeacock@wakehealth.edu (J.E.P.J.); twierzba@wakehealth.edu (T.F.W.); imunawar@wakehealth.edu (I.M.); jwsander@wakehealth.edu (J.W.S.III)

2 Department of Internal Medicine, Section on Cardiovascular Medicine, Wake Forest School of Medicine, Winston-Salem, NC 27517, USA; aseals@wakehealth.edu (A.L.S.); dherring@wakehealth.edu (D.M.H.)

3 Biostatistics Center, George Washington University Milken School of Public Health, Washington, DC 20052, USA; sharone@bsc.gwu.edu

4 Jerry M. Wallace School of Osteopathic Medicine, Campbell University, Lillington, NC 27546, USA. hinkelman@campbell.edu

5 New Hanover Regional Medical Center, Wilmington, NC 28401, USA; patrick.maguire@nhrmc.org

6 Wake Med Health and Hospitals, Raleigh, NC 27610, USA; blagarde@wakemed.org

7 Atrium Health, Charlotte, NC 28204, USA; michael.runyon@atriumhealth.org (M.S.R.); michael.gibbs@atriumhealth.org (M.A.G.)

8 Vidant Health, Greenville, NC 27834, USA; thomas.gallaher@vidanthealth.com

* Correspondence: cenwezor@wakehealth.edu

+ Contributed equally.

\begin{abstract}
Coronavirus Disease-2019 (COVID-19) vaccine acceptance is variable. We surveyed participants in the COVID-19 Community Research Partnership from 17 December 2020 to 13 January 2021 to assess vaccine receptiveness. Vaccine uptake was then monitored until 15 May 2021; 20,232 participants responded to the receptiveness survey with vaccination status accessed in 18,874 participants via daily follow-up surveys (participants not completing daily surveys $\geq 30$ days to 15 May 2021, were excluded). In the initial survey, 4802 (23.8\%) were vaccine hesitant. Hesitancy was most apparent in women (Adjusted RR 0.93, $p<0.001$ ), Black Americans (Adjusted RR 1.39, 1.41, 1.31 to non-Hispanic Whites, Other, and Hispanic or Latino, respectively $p<0.001$ ), healthcare workers (Adjusted RR 0.93, $p<0.001$ ), suburbanites (ref. Urban Adjusted RR 0.85, 0.90 to urban and rural dwellers, respectively, $p<0.01$ ), and those previously diagnosed with COVID-19 (RR 1.20, $p<0.01$ ). Those $<50$ years were also less accepting of vaccination. Subsequent vaccine uptake was $99 \%$ in non-hesitant participants. For those who were unsure, preferred not to answer, or answered "no", vaccination rates were $80 \%$ (Adjusted RR 0.86, $p<0.0001$ ), 78\% (Adjusted RR 0.83, $p<0.0001$ ), and 52.7\% (Adjusted RR 0.65, $p<0.0001)$, respectively. These findings suggest that initial intent did not correlate with vaccine uptake in our cohort.
\end{abstract}

Keywords: vaccine hesitancy; vaccine intent; COVID-19; survey; North Carolina; vaccination; vaccine uptake; demographic groups

\section{Introduction}

Three COVID-19 vaccines have been approved for Emergency Use Authorization (EUA) in the United States by the Food and Drug Administration (FDA) [1] Vaccine acceptance and willingness to undergo vaccination are not universal with some national 
surveys suggesting that only $50-55 \%$ of respondents would be willing to receive the COVID-19 vaccine [2,3]. In North Carolina, early polls revealed intent at only 40-45\% [4].

To assess the extent of vaccine hesitancy in North Carolina, we conducted a survey between 17 December 2020, and 13 January 2021, of 20,232 individuals affiliated with five medical centers from differing geographic regions of North Carolina. This was followed by a daily survey of respondents from the same cohort to determine subsequent vaccine uptake rates. This report presents the key findings from those two surveys.

\section{Materials and Methods}

The COVID-19 Community Research Partnership (CCRP) is a multi-site, prospective study combining daily electronic symptom surveillance, longitudinal serologic surveillance, and electronic health record capture [5]. Demographic and survey data are collected via a secure, HIPAA-compliant, online portal. The study has received approval by a centralized Institutional Review Board (Wake Forest Baptist Health). Five of the 10 CCRP sites participated in this sub-study. Those sites were Campbell University in Buies Creek, NC, New Hanover Regional Medical Center in Wilmington, NC, Wake Forest Baptist Health in Winston-Salem, NC, WakeMed Health and Hospitals in Raleigh, NC, and Vidant Health, in Greenville, NC.

Basic demographic data captured for all CCRP participants included age, sex, previous COVID-19 diagnosis status, community of residence, and race/ethnicity. Counties of residence were characterized as urban, suburban, or rural utilizing the North Carolina rural center counties map. Densities were calculated based on the 2014 census population estimates [6] Participants were also classified as to whether they were healthcare workers with all healthcare-related vocations and disciplines included in that category. In addition to the daily CCRP surveys where participants are asked questions about COVID-like symptoms, infections, and their vaccination status, they were asked to complete a single multiple-choice mini-survey on attitudes about COVID-19 vaccination. Participants completed these surveys using an online Patient Monitoring System application developed by Oracle Corporation (Redwood, CA, USA). There were four choices for vaccine intent: yes, no, undecided, and prefer not to answer. For participants who did not respond "yes" to the vaccine intent question, a follow-up question asked participants to specify reasons for vaccine hesitancy (Figure 1). The vaccine attitudes survey data was collected between 17 December 2020 and 13 January 2021.

To correlate the association of demographic characteristics with vaccine intent, binomial regression was implemented. Vaccine intent responses were categorized into two groups for this analysis: Yes and No/Undecided. To assess how demographic characteristics were associated with vaccine receptiveness, multivariate binomial regression was used with a log link function. The resulting coefficient estimates were exponentiated (eb) to calculate relative risk. The relative risk of responding 'Yes' was calculated for each demographic variable, along with 95\% confidence intervals. Previous COVID-19 Diagnosis was self-reported information included as a part of the enrollment questionnaire (Supplementary materials). The impact of a prior diagnosis of COVID-19 on vaccine receptiveness was also analyzed in a similar fashion. $p$-values $<0.001$ were considered significant.

In addition to the vaccine attitudes survey, daily CCRP survey data through 15 May 2021, was used to assess which participants reported receiving at least one COVID19 vaccine dose. The vaccine rate was stratified by the vaccine intent and participants' characteristics (Tables 1 and 2). Unvaccinated participants who did not complete the daily CCRP survey 30 days or more prior to 15 May 2021 were excluded from the vaccine rate calculation. All statistical analysis was performed using SAS 9.4 (SAS Institute, Cary, NC, USA). 


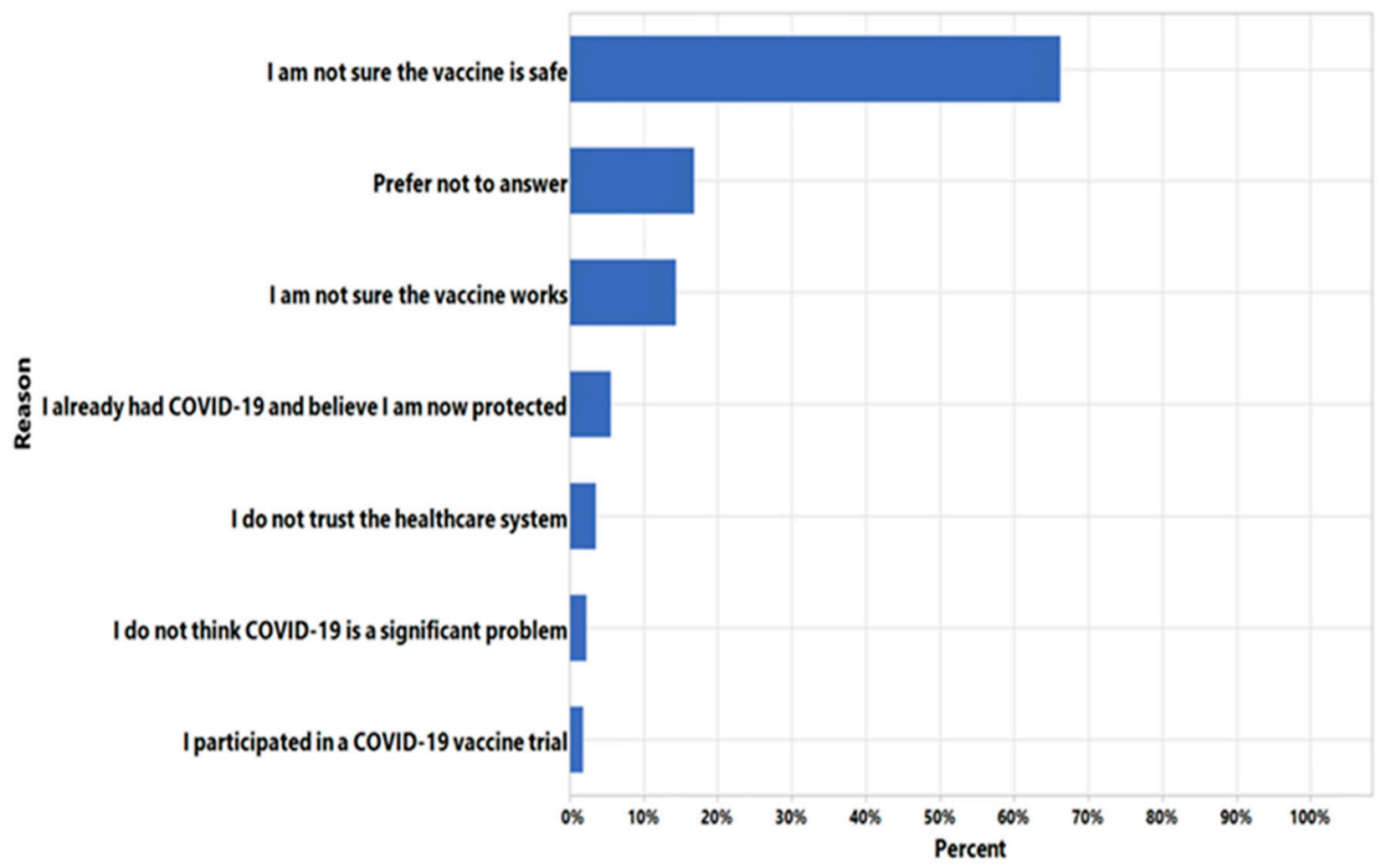

Figure 1. Reasons given by participants who did not respond "yes" on the survey.

Table 1. Vaccine intent and vaccination status with Relative Risk of being vaccinated. $n-$ number, CI—confidence interval, ref-reference.

\begin{tabular}{|c|c|c|c|c|c|c|c|c|}
\hline & \multirow{3}{*}{$\begin{array}{c}\text { Total } \\
\mathbf{n}\end{array}$} & \multicolumn{4}{|c|}{ Vaccine Status } & \multirow[b]{3}{*}{ Relative Risk } & \multirow[b]{3}{*}{$95 \% \mathrm{CI}$} & \multirow[b]{3}{*}{$p$-Value } \\
\hline & & \multicolumn{2}{|c|}{ Vaccinated } & \multicolumn{2}{|c|}{ Non-Vaccinated } & & & \\
\hline & & $\mathbf{n}$ & Percent & $\mathbf{n}$ & Percent & & & \\
\hline TOTAL & 18,874 & 17,461 & 92.5 & 1413 & 7.5 & & & \\
\hline \multicolumn{9}{|l|}{ Vaccine Intent } \\
\hline Yes & 14,810 & 14,582 & 98.5 & 228 & 1.5 & ref. & ref. & ref. \\
\hline No & 1358 & 715 & 52.7 & 643 & 47.3 & 0.65 & $0.62-0.67$ & $<0.0001$ \\
\hline Undecided & 2403 & 1929 & 80.3 & 474 & 19.7 & 0.86 & $0.84-0.87$ & $<0.0001$ \\
\hline Prefer no to answer & 303 & 235 & 77.6 & 68 & 1.6 & 0.83 & $0.79-0.88$ & $<0.0001$ \\
\hline
\end{tabular}

Table 2. Vaccination status by participant characteristics.

\begin{tabular}{|c|c|c|c|c|c|}
\hline & \multirow{3}{*}{$\begin{array}{c}\text { Total } \\
\mathbf{n}\end{array}$} & \multicolumn{4}{|c|}{ Vaccine Status } \\
\hline & & \multicolumn{2}{|c|}{ Vaccinated } & \multicolumn{2}{|c|}{ Non-Vaccinated } \\
\hline & & $\mathrm{n}$ & Percent & $\mathrm{n}$ & Percent \\
\hline TOTAL & 18,874 & 17,462 & 92.5 & 1413 & 7.5 \\
\hline \multicolumn{6}{|l|}{ SEX } \\
\hline Women & 12,835 & 11,780 & 91.8 & 1055 & 8.2 \\
\hline Men & 6039 & 5681 & 94.1 & 358 & 5.9 \\
\hline \multicolumn{6}{|c|}{ AGE GROUP } \\
\hline$<30$ & 895 & 804 & 89.8 & 91 & 10.2 \\
\hline
\end{tabular}


Table 2. Cont.

\begin{tabular}{|c|c|c|c|c|c|}
\hline & \multirow{3}{*}{$\begin{array}{c}\text { Total } \\
\mathbf{n} \\
\end{array}$} & \multicolumn{4}{|c|}{ Vaccine Status } \\
\hline & & \multicolumn{2}{|c|}{ Vaccinated } & \multicolumn{2}{|c|}{ Non-Vaccinated } \\
\hline & & $\mathbf{n}$ & Percent & $\mathbf{n}$ & Percent \\
\hline $30-39$ & 2766 & 2483 & 89.8 & 283 & 10.2 \\
\hline $40-49$ & 3577 & 3197 & 89.4 & 380 & 10.6 \\
\hline $50-59$ & 4001 & 3636 & 90.9 & 365 & 9.1 \\
\hline $60-69$ & 4715 & 4503 & 95.5 & 212 & 4.5 \\
\hline $70+$ & 2920 & 2838 & 97.2 & 82 & 2.8 \\
\hline \multicolumn{6}{|l|}{ ETHNICITY } \\
\hline Black or African American & 811 & 721 & 88.9 & 90 & 11.1 \\
\hline Hispanic or Latino & 379 & 350 & 92.3 & 29 & 7.7 \\
\hline Other & 692 & 643 & 92.9 & 49 & 7.1 \\
\hline White (not Hispanic/Latino) & 16,992 & 15,747 & 92.7 & 1245 & 7.3 \\
\hline \multicolumn{6}{|l|}{ HEALTHCARE WORKER } \\
\hline $\mathrm{N}$ & 13,997 & 12,956 & 92.6 & 1041 & 7.4 \\
\hline Y & 4877 & 4505 & 92.4 & 372 & 7.6 \\
\hline \multicolumn{6}{|l|}{ PREVIOUS COVID-19 DIAGNOSIS } \\
\hline $\mathrm{N}$ & 18,482 & 17,140 & 92.7 & 1342 & 7.3 \\
\hline $\mathrm{Y}$ & 392 & 321 & 81.9 & 71 & 18.1 \\
\hline \multicolumn{6}{|l|}{ SITE } \\
\hline Campbell University & 134 & 123 & 91.8 & 11 & 8.2 \\
\hline New Hanover Regional Medical Center & 612 & 576 & 94.1 & 36 & 5.9 \\
\hline Vidant Health & 873 & 804 & 92.1 & 69 & 7.9 \\
\hline Wake Forest Baptist Health & 15,022 & 13,835 & 92.1 & 1187 & 7.9 \\
\hline WakeMed Health and Hospitals & 2233 & 2123 & 95.1 & 110 & 4.9 \\
\hline \multicolumn{6}{|l|}{ COUNTY CLASS } \\
\hline Rural & 6118 & 5521 & 90.2 & 597 & 9.8 \\
\hline Suburban & 1533 & 1355 & 88.4 & 178 & 11.6 \\
\hline Urban & 11,223 & 10,585 & 94.3 & 638 & 5.7 \\
\hline
\end{tabular}

\section{Results}

A total of 20,232 people completed the initial mini-survey (Campbell University, $\mathrm{n}=147$; New Hanover Regional Medical Center, $\mathrm{n}=641$; Wake Forest Baptist Health, $\mathrm{n}=16,058$; Wake-Med Health and Hospitals, $\mathrm{n}=2419$; and Vidant Health, $\mathrm{n}=967$ ). The follow-up survey was completed by 18,874 respondents of the same cohort. This decrease in number of participants was due to exclusion of unvaccinated individuals who did not complete the daily follow-up survey 30 days or more prior to 15 May 2021.

In the initial survey, $76.2 \%$ of participants indicated their intent to get the vaccine. Participants were grouped by race, gender, age, residence locale, healthcare worker status, and previous COVID-19 infection (Table 3). Comparative analysis showed that the most likely respondents to get the vaccine were non-Hispanic Whites, males, urban dwellers, and non-healthcare workers (Table 4). Respondents with no previous COVID-19 diagnosis were also more likely to accept the vaccine. Intent to get the vaccine increased with age, with those $>70$ years most likely to get the vaccine. A total of $4810(23.8 \%)$ participants in the initial survey did not answer "yes" to getting the vaccine. Black Americans were the 
least likely to show intent to get the vaccine. By residence locale, suburban residents were the least likely to get the vaccine and by age, those aged 40-49 showed the least intent to get vaccinated. The most common reasons for not accepting the vaccine, were concerns about safety (67\%) and efficacy (15\%) (Figure 1).

Table 3. Vaccine intent responses grouped by sex, age, race \& ethnicity, healthcare worker status, previous COVID-19 diagnosis, Site and county class. $\mathrm{n}-\mathrm{no} ; \mathrm{P}$ - prefer not to answer; $\mathrm{N}-\mathrm{no} ; \mathrm{Y}-\mathrm{yes}$.

\begin{tabular}{|c|c|c|c|c|c|}
\hline & \multirow{3}{*}{$\begin{array}{c}\text { Total } \\
\mathbf{n}\end{array}$} & \multicolumn{4}{|c|}{ Vaccine Intent } \\
\hline & & \multicolumn{2}{|c|}{ No/Undecided/Prefer Not to Answer } & \multicolumn{2}{|c|}{ Yes } \\
\hline & & $\mathbf{N}$ & Percent & n & Percent \\
\hline TOTAL & 20,232 & 4810 & 23.8 & 15,422 & 76.2 \\
\hline \multicolumn{6}{|l|}{ SEX } \\
\hline Women & 13,784 & 3688 & 26.8 & 10,096 & 73.2 \\
\hline Men & 6448 & 1122 & 17.4 & 5326 & 82.6 \\
\hline \multicolumn{6}{|l|}{ AGE GROUP } \\
\hline$<30$ & 1096 & 322 & 29.4 & 774 & 70.6 \\
\hline $30-39$ & 3086 & 889 & 28.8 & 2197 & 71.2 \\
\hline $40-49$ & 3897 & 1175 & 30.2 & 2722 & 69.8 \\
\hline $50-59$ & 4256 & 1180 & 27.7 & 3076 & 72.3 \\
\hline $60-69$ & 4898 & 865 & 17.7 & 4033 & 82.3 \\
\hline $70+$ & 2999 & 379 & 12.6 & 2620 & 87.4 \\
\hline \multicolumn{6}{|l|}{ ETHNICITY/RACE } \\
\hline Black or African American & 932 & 426 & 45.7 & 506 & 54.3 \\
\hline Hispanic or Latino & 413 & 122 & 29.5 & 291 & 70.5 \\
\hline Other & 758 & 179 & 23.6 & 579 & 76.4 \\
\hline White (not Hispanic/Latino) & 18,129 & 4083 & 22.5 & 14,046 & 77.5 \\
\hline \multicolumn{6}{|l|}{ HEALTHCARE WORKER } \\
\hline $\mathrm{N}$ & 15,062 & 3466 & 23 & 11,596 & 77 \\
\hline $\mathrm{Y}$ & 5170 & 1344 & 26 & 3826 & 74 \\
\hline \multicolumn{6}{|l|}{ PREVIOUS COVID-19 DIAGNOSIS } \\
\hline $\mathrm{N}$ & 19,756 & 4624 & 23.4 & 15,132 & 76.6 \\
\hline $\mathrm{Y}$ & 476 & 186 & 39.1 & 290 & 60.9 \\
\hline \multicolumn{6}{|l|}{ SITE } \\
\hline Campbell University & 147 & 48 & 32.7 & 99 & 67.3 \\
\hline New Hanover Regional Medical Center & 641 & 100 & 15.6 & 541 & 84.4 \\
\hline Vidant Health & 967 & 285 & 29.5 & 682 & 70.5 \\
\hline Wake Forest Baptist Health & 16,058 & 3917 & 24.4 & 12,141 & 75.6 \\
\hline WakeMed Health and Hospitals & 2419 & 460 & 19 & 1959 & 81 \\
\hline \multicolumn{6}{|l|}{ COUNTY CLASS } \\
\hline Rural & 6645 & 1916 & 28.8 & 4729 & 71.2 \\
\hline Suburban & 1669 & 530 & 31.8 & 1139 & 68.2 \\
\hline Urban & 11,918 & 2364 & 19.8 & 9554 & 80.2 \\
\hline
\end{tabular}


Table 4. Vaccine acceptance multivariate analysis grouped by sex, age, race \& ethnicity, healthcare worker status, previous COVID-19 diagnosis, Site and county class. CI-Confidence interval; ChiSq-Chi square. Ref.-reference group.

\begin{tabular}{|c|c|c|c|c|c|}
\hline \multirow[b]{2}{*}{ Parameter } & & \multicolumn{4}{|c|}{ Vaccine Acceptance Multivariate Model Estimates } \\
\hline & & Estimate & Adj. Relative Risk & Relative Risk 95\% CI & Pr $>$ ChiSq \\
\hline \multirow[t]{2}{*}{ SEX } & Women & -0.07 & 0.93 & $0.92-0.94$ & $<0.0001$ \\
\hline & Men & ref. & ref. & ref. & \\
\hline \multirow[t]{6}{*}{ AGE GROUP } & $<30$ & -0.17 & 0.85 & $0.81-0.88$ & $<0.0001$ \\
\hline & 30-39 & -0.16 & 0.85 & $0.83-0.87$ & $<0.0001$ \\
\hline & $40-49$ & -0.17 & 0.84 & $0.82-0.86$ & $<0.0001$ \\
\hline & $50-59$ & -0.15 & 0.86 & $0.84-0.88$ & $<0.0001$ \\
\hline & $60-69$ & -0.03 & 0.97 & $0.95-0.98$ & 0.0001 \\
\hline & $\geq 70$ & ref. & ref. & ref. & \\
\hline \multirow[t]{4}{*}{ ETHNICITY/RACE } & Hispanic or Latino & 0.27 & 1.31 & $1.20-1.42$ & $<0.0001$ \\
\hline & Other & 0.34 & 1.41 & $1.32-1.51$ & $<0.0001$ \\
\hline & $\begin{array}{c}\text { White (not } \\
\text { Hispanic/Latino) }\end{array}$ & 0.33 & 1.39 & $1.31-1.48$ & $<0.0001$ \\
\hline & $\begin{array}{c}\text { Black or African } \\
\text { American }\end{array}$ & ref. & ref. & ref. & \\
\hline \multirow[t]{2}{*}{ HEALTHCARE WORKER } & No & -0.03 & 0.97 & $0.96-0.99$ & 0.0014 \\
\hline & Yes & ref. & ref. & ref. & \\
\hline \multirow[t]{2}{*}{$\begin{array}{l}\text { PREVIOUS COVID-19 } \\
\text { DIAGNOSIS }\end{array}$} & No & 0.18 & 1.20 & $1.11-1.28$ & $<0.0001$ \\
\hline & Yes & ref. & ref. & ref. & \\
\hline \multirow[t]{3}{*}{ COUNTY CLASS } & Rural & -0.10 & 0.90 & $0.89-0.92$ & $<0.0001$ \\
\hline & Suburban & -0.16 & 0.85 & $0.83-0.88$ & $<0.0001$ \\
\hline & Urban & ref. & ref. & ref. & \\
\hline
\end{tabular}

The follow-up survey revealed some interesting data about vaccine uptake in these groups. Overall, of the 18,874 individuals that participated in the daily survey until 15 May 2021, 17,461 (92.5\%) obtained a COVID-19 vaccine. Among the participants that had intent to get the vaccine, there was a $98.5 \%$ vaccine uptake. Of those who did not answer "yes" to the initial survey, there was a 70\% vaccine uptake (Table 1). Within this group, there was an $80 \%$ (Adjusted RR 0.86, $p<0.0001$ ) vaccine uptake among those that were undecided, $77.6 \%$ (Adjusted RR 0.83, $p<0.0001$ ) uptake among those that preferred not to answer, and a $52.7 \%$ (Adjusted RR 0.65, $p<0.0001$ ) uptake among those that answered "no" to getting the vaccine in the initial survey.

Interestingly, Black Americans who were the least likely to accept the vaccine based on expressed pre-vaccination attitudes had an $88.9 \%$ vaccine uptake (Table 2 ). There was no difference in vaccination between healthcare workers and non-healthcare workers. Reported vaccination was $>89 \%$ in all age ranges, with those $>70$-years with the highest vaccine uptake (97.2\%). Males had a higher uptake than females (94\% v 91.8\%). Suburban dwellers, who were least likely to indicate vaccine acceptance in the initial survey, had an $88.4 \%$ uptake. Those respondents who reported no previous COVID-19 diagnosis were more likely to be vaccinated than to those with a previous COVID-19 diagnosis (92.7\% v 81.9\%). Despite this difference, uptake in those with a previous COVID-19 diagnosis was higher than expected given that only $60.9 \%$ had intent to get the vaccine. 


\section{Discussion}

Multiple surveys have looked at COVID-19 vaccine hesitancy [2,3,7-10] Surveys conducted before and in the early phases of the vaccine rollout showed vaccine hesitancy of $50-55 \%$. Black, indigenous, and people of color (BIPOC) communities, which are disproportionately affected by the pandemic, had the highest level of hesitancy [11-14]. Recent data have shown a change in attitudes in BIPOC communities $[15,16]$. This is a trend that seems to be the same across all categories represented in our survey. What is especially noteworthy is that vaccine uptake is quite high in those participants that were undecided or preferred not to answer. This observation emphasizes the dynamic nature of vaccine hesitancy. Vaccine hesitancy exists along a spectrum with the extremes of the spectrum being those who completely refuse and those who completely accept vaccines [17]. Individuals within this spectrum are not static and may shift across the spectrum over time, depending upon the current social and clinical context and available vaccine options. In the setting of the COVID-19 pandemic, time is of the essence because the faster we get to herd immunity, the better our chances of avoiding emergence of virulent and evasive variants [18]. Increasing uptake in those in the middle of the spectrum (refuse but unsure, undecided, accept but unsure) may help us achieve herd immunity. Although we did not look at what led to changes in attitudes, it is likely that public health educational interventions which increased confidence in the safety and efficacy of the COVID-19 vaccine may have led individuals in the continuum of vaccine hesitancy to shift towards acceptance [19-21]. A July 2021, vaccine monitor report by the Kaiser Family Foundation found that previously hesitant individuals changed their minds because of influences from family, friends, and personal doctors [22]. As we attempt to reach herd immunity, it is important that we recognize what impact these interventions have and implement them in communities with high levels of vaccine hesitancy and low uptake.

There are several potential limitations of this study. First, our data represent responses from North Carolinians enrolled into an ongoing research study through regional healthcare systems and may not be representative of national data. Our study volunteers are likely to be better connected to a healthcare system and more comfortable with electronic communication than the general community. Second, this survey provides only a snapshot in time and, as demonstrated by out follow-up survey, attitudes do change over time. Third, the demographics of our survey participants may not reflect national demographics. Fourth, our finding of more hesitancy among suburban residents may simply reflect limitations in our method for characterizing counties as it is difficult to accurately describe many counties in North Carolina as entirely urban, suburban, or rural. Fifth, we did not detail the reasons why our participants had a change in attitude trending towards increased acceptance. Finally, survey results might not be comparable to other national or state polls or surveys due to potential differences in survey methods, sample population, and questions related to willingness to get the vaccine.

In conclusion, this survey examined attitudes towards the COVID-19 vaccine in the initial phases of the vaccine rollout, and then followed the same cohort over subsequent months looking at uptake. Initial intent did not correlate with uptake in our North Carolina cohort. Vaccine uptake in participants that did not answer "yes" to the initial survey was $70 \%$ which offers some insight that broader acceptance of vaccination may continue to evolve over time.

Supplementary Materials: The following are available online at https://www.mdpi.com/article/10 .3390/vaccines9080916/s1. QUESTIONNAIRE: COVID-19 Vaccine Survey.

Author Contributions: C.H.E. served as lead author. A.L.S. contributed to the analysis of the results. J.E.P.J., J.W.S.III, D.M.H., A.N.H., S.L.E., T.F.W., I.M., P.D.M., M.A.G., M.S.R., W.H.L., T.R.G. All contributed to the design and implementation of the research, and to the writing of the manuscript. All authors have read and agreed to the published version of the manuscript.

Funding: This work was supported by the Coronavirus Aid, Relief, and Economic Security (CARES) Act by the U.S. Department of the Treasury. NC DHHS GTS \#49927. 
Institutional Review Board Statement: The study was conducted according to the guidelines of the Declaration of Helsinki and approved by the Institutional Review Board of Wake Forest School of Medicine Institutional Review Board, protocol [IRB00064912].

Informed Consent Statement: Informed consent was obtained from all subjects involved in the study.

Data Availability Statement: The datasets used and/or analyzed during the current study are available from the corresponding author upon request.

Acknowledgments: COVID-19 Community Research Partnership Study Group: Wake Forest School of Medicine: John Walton Sanders, Thomas F Wierzb, David Herrington, Mark A. Espeland, Morgana Mongraw-Chaffin, Alain Bertoni, Martha A. Alexander-Miller, Allison Mathews, Iqra Munawar, Austin Lyles Seals, Brian Ostasiewski, Christine Ann Pittman Ballard, Metin Gurcan, Alexander Ivanov, Allison Matthews, Giselle Melendez Zapata, Marlena Westcott, Karen Blinson, Laura Blinson, Douglas McGlasson, Mark Mistysyn, Donna Davis, Lynda Doomy, Perrin Henderson, Alicia Jessup, Kimberly Lane, Beverly Levine, Jessica McCanless, Sharon McDaniel, Kathryn Melius, Christine O’Neill, Angelina Pack, Ritu Rathee, Scott Rushing, Jennifer Sheets, Sandra Soots, Michele Wall, Samantha Wheeler, John White, Lisa Wilkerson, Rebekah Wilson, Kenneth Wilson, Deb Burcombe. Atrium Health: Michael S. Runyon, Lewis H. McCurdy, Michael A. Gibbs, Yhenneko J. Taylor, Lydia Calamari, Hazel Tapp, Amina Ahmed, Michael Brennan, Lindsay Munn, Keerti L. Dantuluri, Timothy Hetherington, Lauren C. Lu, Connell Dunn, Melanie Hogg, Andrea Price, Marina Leonidas, Laura Staton, Kenniesha Spencer, Melinda Manning, Whitney Rossman, Frank X. Gohs, Anna Harris, MPH, Bella Gutnik, Jennifer S. Priem, Ryan Burns, Med-Star Health Research Institute: William Weintraub, Kristen Miller, Chris Washington, Allison Moses, Sarahfaye Dolman, Julissa ZelayaPortillo, John Erkus, Joseph Blumenthal, Ronald E. Romero Barrientos, Sonita Bennett, Shrenik Shah, Shrey Mathur, Christian Boxley, Paul Kolm, Long La, Cheng Zhang, Eva Hochberger, Ella Franklin, Deliya Wesley, Naheed Ahmed. Tulane: Richard Oberhelman, Joseph Keating, Patricia Kissinger, John Schieffelin, Joshua Yukich, Andrew "AJ" Beron, Devin Hayes, Johanna Teigen. University of Maryland School of Medicine: Karen Kotloff, Wilbur Chen, DeAnna Friedman-Klabanoff, Andrea A. Berry, Helen Powell, Lynnee Roane, Reva Datar, University of Mississippi: Adolfo Correa, Leandro Mena, Bhagyashri Na-valkele, Yuan-I Min, Alexandra Castillo, Lori Ward, Robert P. Santos, Courtney Gomillia, Pramod Anugu, Yan Gao, Jason Green, Ramona Sandlin, Donald Moore, Lemichal Drake, Dorothy Horton, Kendra L. Johnson, Wake Med Health and Hospitals: William H. Lagarde, LaMonica Daniel, New Hanover: Patrick D. Maguire, Charin L. Hanlon, Lynette McFayden, Isaura Rigo, Kelli Hines, Lindsay Smith, Alexa Drilling, Monique Harris, Belinda Lissor, Vivian Cook, Maddy Eversole, Terry Herrin, Dennis Murphy, Lauren Kinney, Polly Diehl, Nicholas Abromitis, Tina St. Pierre, Judy Kennedy BSCS, MBA, Lauren Kinney, Bill Heckman, Denise Evans, Vivian Cook, Maddy Eversole, Julian March, Ben Whitlock, Wendy Moore. Vidant Health: Shakira Henderson, MPH, Thomas R. Gallaher, Michael Zimmer, Danielle Oliver, Tina Dixon, Kasheta Jackson, Martha Reavis, Monica Menon, Brandon Bishop, Rachel Roeth, Mathew Johanson, Alesia Ceaser, Amada Fernandez, Carmen Williams, Jeremiah Hargett, Keeaira Boyd, Kevonna Forbes, Latasha Thomas, Markee Jenkins, Monica Coward, Derrick Clark, Omeshia Frost, Angela Darden, Lakeya Askew, Sarah Phipps, Victoria Barnes. Campbell University School of Osteo-pathic Medicine: Robin King-Thiele, Terri S. Hamrick, Chika Okafor (Cape Fear Valley Medical Center), Regina B. Bray Brown (Harnett Health System, Inc.), Pinoorma Vinod (Southeastern Health), Lawrence Klima (Harnett Health System), Amber Brewster (Harnett Health System), Danius Bouyi (Harnett Health System), Katrina Lamont (Harnett Health System), Kazumi Yoshinaga (Harnett Health S ystem), Abdalla Ihmeidan (Campbell University School of Osteo-pathic Medicine), A. Suman Peela (Southeastern Health System), Giera Denbel (Southeastern Health System), Jason Lo,: Southeastern Health System, Mariam Mayet-Khan (Southeastern Health System), Akash Mittal (Southeastern Health System), Reena Motwani (Southeastern Health System), Mohamed Raafat (Southeastern Health System), Evan Schultz (Cumberland County Hospital System, Cape Fear Valley), Aderson Joseph (Cumberland County Hospital System, Cape Fear Valley), Aalok Parkeh (Cumberland County Hospital System, Cape Fear Val-ley), Dhara Patel (Cumberland County Hospital System, Cape Fear Valley), Babar Afridi (Cum-berland County Hospital System, Cape Fear Valley) George Washington University Data Coor-dinating Center: Diane Uschner, Sharon L Edelstein, ScM, Michele Santacatterina, Greg Strylew-icz, Brian Burke, Mihili Gunaratne, Meghan Turney, Shirley Qin Zhou, Ashley H Tjaden, Lida Fette, Asare Buahin, Matthew Bott, Sophia Graziani Oracle Corporation: Rebecca Laborde Vysnova Partners: Anne McKeague, Grace Tran, Johnathan Ward, Joyce Dieterly, Nana Darko, Kimberly Castellon, Isabella Malcolm, Ryan Brink, Haris Shehzad, Derek Kuprianov Javara Inc: Atira Goodwin External Advisory Council: Ruth Berkelman, Emory, 
Kimberly Hanson, U of Utah, Scott Zeger, Johns Hopkins, Cavan Reilly, U. of Minnesota, Kathy Edwards, Vanderbilt, Helene Gayle, Chicago Community Trust.

Conflicts of Interest: The authors declare no conflict of interest. The funders had no role in the design of the study; in the collection, analyses, or interpretation of data; in the writing of the manuscript; or in the decision to publish the results.

$\begin{array}{ll}\text { Abbreviations } \\ \text { BIPOC } & \text { Blacks, Indigenous and People of color } \\ \text { CCRP } & \text { COVID-19 Community Research Partnership } \\ \text { CDC } & \text { Centers for Disease Control and Prevention } \\ \text { COVID-19 } & \text { Coronavirus disease 2019 } \\ \text { EUA } & \text { Emergency Use Authorization } \\ \text { FDA } & \text { Food and Drug Administration } \\ \text { NC } & \text { North Carolina } \\ \text { US } & \text { United States }\end{array}$

\section{References}

1. COVID-19 Vaccines. Available online: https://www.fda.gov/emergency-preparedness-and-response/coronavirus-disease-2019 -covid-19/covid-19-vaccines (accessed on 27 April 2021).

2. Hamel, L. KFF COVID-19 Vaccine Monitor; Kaiser Family Foundation (KFF). Available online: https:/ /www.kff.org/coronaviruscovid-19/poll-finding/kff-covid-19-vaccine-monitor-april-2021/ (accessed on 15 May 2021).

3. Salvanto, A.; De Pinto, J.; Backus, F.; Khanna, K. Many Would Get the COVID-19 Vaccine, But Hesitancy Remains-CBS News Poll. 26 February 2021. Available online: https:/ / www.cbsnews.com/news/covid-vaccine-hesitancy-opinion-poll/ (accessed on 27 April 2021).

4. Debruyn, J. Polls Show North Carolinians Are Increasingly Willing to Get COVID-19 Vaccine. 16 February 2021. Available online: https:/ / www.wunc.org/health/2021-02-16/polls-show-north-carolinians-are-increasingly-willing-to-get-covid-19-vaccine (accessed on 27 April 2021).

5. COVID-19 Community Research Partnership. Available online: https://www.wakehealth.edu/Coronavirus/COVID-19 -Community-Research-Partnership (accessed on 19 July 2021).

6. NC Rural Center. North Carolina Counties. Available online: https://www.ncruralcenter.org/about-us/ (accessed on 27 April 2021).

7. Lazarus, J.V.; Ratzan, S.C.; Palayew, A.; Gostin, L.O.; Larson, H.J.; Rabin, K.; Kimball, S.; El-Mohandes, A. A Global Survey of Potential acceptance of a COVID-19 Vaccine. Nat. Med. 2021, 27, 225-228. [CrossRef] [PubMed]

8. Nguyen, K.H.; Srivastav, A.; Razzaghi, H.; Williams, W.; Lindley, M.C.; Jorgensen, C.; Abad, N.; Singleton, J.A. COVID-19 Vaccination Intent, Perceptions, and Reasons for Not Vaccinating Among Groups Prioritized for Early Vaccination-United States, September and December 2020. MMWR 2021, 70, 217-222. [PubMed]

9. Funk, G.; Tyson, A. Growing Share of Americans Say They Plan to Get a COVID-19 Vaccine-Or Already Have-77\% Think Vaccinations Will Benefit U.S. Economy. Pew Center Research Science and Society. 5 March 2021. Available online: https:/ / www.pewresearch.org/science/2021/03/05/growing-share-of-americans-say-they-plan-to-get-a-covid-19-vaccineor-already-have/ (accessed on 30 April 2021).

10. Khubchandani, J.; Sharma, S.; Price, J.H.; Wiblishauser, M.J.; Sharma, M.; Webb, F.J. COVID-19 Vaccination Hesitancy in the United States: A Rapid National Assessment. J. Community Health 2020, 46, 270-277. [CrossRef] [PubMed]

11. Gold, J.A.; Rossen, L.M.; Ahmad, F.B.; Sutton, P.; Li, Z.; Salvatore, P.P.; Coyle, J.; DeCuir, J.; Baack, B.; Durant, T.; et al. Race, Ethnicity, and Age Trends in Persons Who Died from COVID-19-United States, May-August 2020. MMWR 2020, 69, 1517-1521. [PubMed]

12. APM Research Lab Staff. The Color of Coronavirus: COVID-19 Deaths by Race and Ethnicity in the U.S. 5 March 2021. Available online: https:/ / www.apmresearchlab.org/covid/deaths-by-race (accessed on 28 April 2021).

13. Fletcher, M.A. New poll shows Black Americans see a racist health care system setting the stage for pandemic's impact even as they lose family members and jobs, most are reluctant to try a vaccine. Undefeated 2020. Available online: https://theundefeated.com/ features /new-poll-shows-black-americans-see-a-racist-health-care-system-setting-the-stage-for-pandemics-impact/ (accessed on 28 April 2021).

14. O'Neal, L. Half of Black adults say they won't take a coronavirus vaccine. Undefeated 2020. Available online: https:// theundefeated.com/features/half-of-black-adults-say-they-wont-take-a-coronavirus-vaccine/ (accessed on 28 April 2021).

15. Summers, J. Little Difference in Vaccine Hesitancy among White and Black Americans, Poll Finds. 12 March 2021. Available online: https:/ / www.npr.org/ (accessed on 28 April 2021). 
16. Huetteman, E. Covid vaccine hesitancy drops among all Americans, new survey shows. KHN 2021. Available online: https: //www.healthleadersmedia.com/covid-19/covid-vaccine-hesitancy-drops-among-all-americans-new-survey-shows (accessed on 29 April 2021).

17. Violette, R.; Pullagura, G.R. Vaccine hesitancy: Moving practice beyond binary vaccination outcomes in community pharmacy. Can. Pharm. J. 2019, 152, 391-394. [CrossRef] [PubMed]

18. Mascola, J.R.; Graham, B.S.; Fauci, A.S. SARS-CoV-2 Viral Variants-Tackling a Moving Target. JAMA 2021, 325, 1261-1262. [CrossRef] [PubMed]

19. Bunn, C. 'Getting a clearer picture': Black Americans on the Factors That Overcame Their Vaccine Hesitancy. NBC News, 12 April 2021. Available online: https://www.nbcnews.com/news/nbcblk/getting-clearer-picture-black-americans-factors-overcametheir-vaccine-hesitancy-n1263787(accessed on 29 April 2021).

20. Working Group on Equity in COVID-19 Vaccination; John Hopkins School of Public Health. Equity in Vaccination: A Plan to Work with Communities of Color toward COVID-19 Recovery and Beyond. February 2021. Available online: https://www. centerforhealthsecurity.org/ (accessed on 30 April 2021).

21. CDC COVID-19 Task Force. Building Confidence in COVID-19 Vaccines among Your Patients. Tips for Healthcare Teams. January 2021. Available online: https://www.cdc.gov/vaccines/covid-19/downloads/VaccinateWConfidence-TipsForHCTeams_508.pdf (accessed on 30 April 2021).

22. Craig Palosky. Vaccine Monitor: Some Who Were Hesitant to Get a Vaccine in January Say They Changed Their Mind Because of Family, Friends and Their Personal Doctors. 13 July 2020. Available online: https://www.kff.org/coronavirus-covid-19 / press-release/vaccine-monitor-some-who-were-hesitant-to-get-a-vaccine-in-january-say-they-changed-their-mind-becauseof-family-friends-and-their-personal-doctors/ (accessed on 30 April 2021). 